\title{
STRES KERJA DAN KINERJA : META ANALISIS
}

\author{
Aulia \\ Fakultas Psikologi, Universitas Ahmad Dahlan \\ J1. Kapas No. 09, Semaki, Yogyakarta \\ auliazenlovemail@gmail.com
}

\begin{abstract}
Performance is an achievement of employee's work, which is an important factor used as an evaluation of the effectiveness within the organization. There are many factors that affect to performance, work stress is one of them. Many studies related work stress and performance have been done with extremely variable results. Therefore, this research aims to review and analyze previous research at the scope of organization industry related with work stress, and performance using meta-analysis approach. The meta-analysis study was performed by reviewing 19 studies based on value selection results, r-correlation, the coefficient of reliability, characteristics of research subjects, and is a primary study. Based on the analysis that has been done by researcher, empirically the result of this meta-analysis study is able to answer and reassure researcher, that the stress level of the employees have negative correlation with performance it self. It means that high work stress on employees will form the distress instead, because it's already past the normal threshold, and as a result the stress can affect mental and physical state of employees, which implies performance degradation.
\end{abstract}

Keywords : meta-analysis, performance, work stress

\begin{abstract}
Abstrak
Kinerja adalah hasil pencapaian kerja karyawan yang merupakan faktor penting untuk digunakan sebagai evaluasi efektivitas kerja individu dalam lingkup organisasi. Banyak faktor yang memengaruhi kinerja, dan salah satunya adalah stres kerja. Studi antara stres kerja dan kinerja sudah banyak dilakukan oleh para peneliti sebelumnya, namun hasil yang diperoleh sangat bervariasi. Oleh karena itu, tujuan penelitian ini mengkaji dan menganalisis hasil penelitian sebelumnya di bidang industri organisasi, yang berhubungan dengan stres kerja dan kinerja dengan pendekatan studi meta analisis. Studi meta analisis yang dilakukan adalah dengan cara mengkaji 19 studi berdasarkan hasil seleksi nilai korelasi r, koefisien reliabilitas, karakteristik subjek penelitian, dan merupakan studi primer. Berdasarkan hasil analisis yang telah dilakukan, secara empirik hasil studi meta analisis ini mampu menjawab sekaligus meyakinkan peneliti bahwa stres kerja yang dialami oleh karyawan memiliki korelasi negatif pada kinerja. Artinya, stres kerja yang tinggi pada karyawan akan membentuk distres karena sudah melewati ambang batas normal, sehingga stres yang dialami dapat memengaruhi kondisi mental dan fisik karyawan yang berimplikasi pada penurunan kinerja.
\end{abstract}

Kata kunci: kinerja, meta analisis, stres kerja 


\section{Pendahuluan}

Kinerja adalah permasalahan klasik tentang perilaku kerja karyawan yang tercermin dalam bentuk hasil pada setiap kegiatan organisasi, namun mengingat pentingnya kinerja bagi kelangsungan hidup organisasi, maka topik ini tidak pernah habis dibahas dalam dunia industri organisasi sampai saat ini. Kinerja secara tradisional memainkan peran sentral dalam pengukuran pekerjaan di bidang psikologi industri-organisasi (Schmidt \& Hunter, 1992; Viswesvaran, Schmidt, \& Ones, 2002). Menurut Yelboga (2012) ukuran kinerja dari suatu pekerjaan memainkan peran penting dalam penelitian dan praktik. Keberhasilan atau kegagalan organisasi tergantung pada kinerja karyawan dalam organisasi. Semakin tinggi kinerja karyawan maka peluang keberhasilan suatu organisasi akan semakin besar, dan sebaliknya semakin rendah kinerja karyawan kemungkinan gagalnya suatu organisasipun akan semakin besar.

Definisi umum dari konstruk kinerja mencerminkan perilaku (baik secara visual diamati dan non-diamati) yang dapat dievaluasi (Viswesvaran, et. al, 1996). Kinerja dapat diartikan sebagai sejauh mana individu melaksanakan tanggung jawab dan tugas kerjanya (Singh, Verbeke \& Rhoads, 1996). Mathis dan Jackson (2002) menjelaskan bahwa kinerja adalah apa yang dikerjakan dan yang tidak dikerjakan oleh karyawan. Kinerja karyawan memengaruhi seberapa banyak karyawan memberikan kontribusi kepada organisasi. Hal ini karena penilaian kinerja karyawan tersebut nantinya dapat digunakan sebagai analisis untuk kebutuhan dilaksanakannya pelatihan (Ivancevich, 2001).

Levey (2001) menjelaskan kinerja sebagai hasil kerja sama dari tiga faktor yang meliputi keterampilan, usaha dan kondisi pekerjaan. Keterampilan meliputi pengetahuan, kemampuan dan kompetensi karyawan dalam pekerjaan; usaha mengarah pada motivasi karyawan mendapatkan pekerjaan yang dilakukan; dan kondisi kerja adalah tingkat akomodasi dari suatu kondisi untuk memfasilitasi produktivitas karyawan. Muchinsky (2003) menyatakan bahwa kinerja adalah pengaturan perilaku karyawan yang dapat dipantau, diukur, dan dinilai berdasarkan prestasi pencapaian individu, selain itu perilaku ini juga terkait dengan tujuan organisasi. Penilaian kinerja merupakan proses evaluasi seberapa baik karyawan mengerjakan pekerjaan mereka ketika dibandingkan dengan satu set standar dan kemudian mengkomunikasikannya dengan para karyawan (Mathis \& Jackson, 2002).

Kinerja karyawan dapat diukur menggunakan metode yang berbeda, namun metode ini dapat diklasifikasikan ke dalam dua kategori besar: 1) catatan organisasi, dan 2) evaluasi subjektif. Catatan organisasi yang dianggap lebih "objektif", berbeda dengan evaluasi "subjektif" yang bergantung pada penilaian manusia (Viswesvaran \& Ones, 2005). Berdasarkan cara yang berbeda untuk mengukur kinerja, maka penilaian kinerja yang paling lazim dan masuk pada kategori subjektif dapat diperoleh dari supervisor, rekan-rekan, bawahan, diri sendiri (mandiri) atau pelanggan, namun supervisor dan rekan kerja menjadi sumber yang paling umum digunakan dalam penilaian (Cascio, 1991; Cleveland, et al., 1989; Viswesvaran, et al., 1996). Smithikrai (dalam Saetang, 2010) ada banyak panel yang dapat memberikan penilaian pada kinerja, dan bahwa setiap penilai memiliki kelebihan dan kekurangan yang berbeda; seperti atasan langsung, rekan kerja, komite, diri sendiri dan bawahan.

Definisi umum dari konstruk kinerja 
mencerminkan perilaku (baik secara visual diamati dan non-diamati) yang dapat dievaluasi, sedangkan dimensi kinerja meliputi dua hal yaitu kualitatif dan kuantitatif (Viswesvaran, et al., 1996). Setelah Viswesvaran, et al., selanjutnya Babin dan Boles (1998); Bono dan Judge (2003) menyarankan penggunaan instrumen pengukuran kinerja dari banyak aspek perilaku spesifik, seperti perilaku inovatif, pengambilan inisiatif, tingkat potensi diri, manajemen waktu, pencapaian kuantitas dan kualitas pekerjaan, kemampuan diri untuk mencapai tujuan, hubungan dengan rekan kerja serta pelanggan, dan pengetahuan akan produk perusahaannya serta produk pesaing (product knowledge). Cara ini menurut Bono dan Judge (2003) selain ditujukan untuk mengatasi bias pengukuran juga dimaksudkan untuk mengakomodir ukuranukuran kinerja yang sangat luas, sehingga diperoleh gambaran job performance yang komprehensif.

Hasil penelitian yang telah dilakukan oleh para peneliti terdahulu telah menemukan faktor-faktor yang memengaruhi kinerja karyawan diantaranya, seperti; kepemimpinan (Singh, et al., 1996), keterikatan/ keterlibatan kerja (Brown, 1996; Diefendorff, Brown, Kamin, \& Lord, 2002; Rotenberry \& Moberg, 2007; Puspita, 2012), tuntutan kerja (Baker, Demerouti, \& Verbeke, 2004). budaya organisasi (Singh, et al., 1996), kepribadian (Mount \& Barrick, 1998; Motowidlo, Borman, \& Schmit, 1997), komitmen (Jaramilloa, Mulki, \& Marshall, 2005; Al Ahmadi, 2009), kepuasan kerja (Judge, Bono, Thoresen, \& Patton, 2001; Gu \& Chi, 2009), pendidikan (Ng \& Feldman, 2009), self-efficacy (Karatepea, Uludagb, Menevisc, Hadzimehmedagicc, \& Baddarc, 2006; D'Amato \& Zijlstra, 2008), pengalaman (Dokko, Wilk, \& Rothbard 2008), stres kerja (Beehr \& Newman, 1988;
Luthans, 1998; Robbins, 2001; Kazmi, Amjad, \& Khan 2008), sikap kerja (Riketta, 2008), ambiguitas peran (Knight, Kim, \& Crutsinger, 2007), kecerdasan emosi (Chermiss, 1998; Boyatzis, 1999; Goleman, 2001), harga diri (Ferris, Lian, Brown, Pang, \& Keeping, 2010).

Banyak faktor yang memengaruhi kinerja karyawan, penelitian ini mengkaji salah satu faktor yang sering diteliti oleh para peneliti sebelumnya yaitu stres kerja yang dialami karyawan. Beberapa hasil penelitian yang menunjukan bahwa stres kerja mempengaruhi naik atau turunnya kinerja karyawan seperti penelitian yang dilakukan oleh Atteya (2012); Chen (2009); Evan dan Johnson (2000); Looker, 2005; Jamal (2012); Wu (2011); Yang dan Hung (2012). Penelitian tentang stres kerja terus berkembang selama beberapa dekade terakhir ini, dan topik ini seakan menjadi topik yang selalu menarik untuk terus dikaji, meskipun hasil penelitian tentang stres kerja dengan kinerja antara satu peneliti dengan peneliti lainnya tidak selalu sama.

Hasil penelitian stres kerja dengan kinerja yang dilakukan oleh para peneliti sebelumnya dalam kurun waktu 10 tahun menunjukkan hasil yang bervariasi, baik menunjukan hubungan negatif ataupun hubungan positif. Hasil penelitian yang dilakukan oleh Hamidi \& Eivazi (2010); dan Ali, et al. (2011) menunjukkan adanya hubungan positif antara stres kerja dengan kinerja. Sebaliknya hasil penelitian Kazmi, et.al., (2008); Mohsan, et.al., (2011); Yang dan Hung (2012) menunjukkan bahwa ada hubungan negatif antara stres kerja dengan kinerja karyawan.

Streskerja merupakan beban kerja yang berlebihan, perasaan susah dan ketegangan emosional yang menghambat performansi individu (Robbins, 2004). Evan dan Johnson (2000) menyebutkan bahwa stres kerja 
merupakan faktor yang menentukan naik turunnya kinerja karyawan. Hasil penelitian Vakola dan Nikolaou (2005) menunjukkan bahwa terdapat pengaruh yang signifikan dari stres kerja yang dialami karyawan dengan perubahan sikap karyawan pada organisasi. Stres kerja dapat berdampak pada terganggunya konsentrasi kerja, kinerja kurang memuaskan dan individu tidak dapat memenuhi tuntutan pekerjaannya (Luthans, 1998). Stres kerja menyebabkan penyimpangan pada fungsi psikologis, fisik dan tingkah laku individu, dan hal tersebut dapat menyebabkan terjadinya penyimpangan dari fungsi normal (Beehr \& Newman, 1988; Robbins, 2001).

Sheridan dan Radmacher (1992) menyebutkan adanya tiga aspek potensial penyebab stres kerja, secara umum, yang meliputi : 1) Aspek lingkungan. Aspek lingkungan yang terjadi di masyarakat terkait dengan kondisi global yang menyebabkan stres kerja, antara lain: ketidakpastian ekonomi berupa perubahan daur bisnis, ketidakpastian politik dan ketidakpastian teknologi yang dapat menyebabkan keterampilan dan pengalaman anggota menjadi usang dalam waktu yang sangat singkat; 2) Aspek organisasional. Aspek organisasional adalah kondisi-kondisi organisasi yang mampu menimbulkan stres kerja, antara lain: a) kondisi intrinsik pekerjaan; b) karakteristik peran; c) karakteristik lingkungan sosial; d) iklim organisasi; e) karakteristik fisik lingkungan kerja; 3) Aspek individual. Aspek individual adalah semua hal yang terdapat dalam kehidupan pribadi individu di luar pekerjaan, seperti masalah keluarga, masalah ekonomi dan karakteristik kepribadian anggota yang rentan terhadap stres.

Pada penelitian ini peneliti mencoba untuk mengkaji hubungan antara stres kerja dengan kinerja menggunakan pendekatan meta-analisis. Meta analisis merupakan studi dengan data yang berasal dari studi primer dan merupakan salah satu cara untuk merangkum berbagai hasil penelitian studi kuantitatif. Studi meta analisis adalah suatu teknik yang ditujukan untuk menganalisis kembali hasil-hasil penelitian sebelumnya yang telah diolah secara statistik berdasarkan pengungkapan data primer. Melalui studi meta analisis, dapat dilakukan pengkoreksian dampak kesalahan pengambilan sampel, kesalahan pengkuran, dan berbagai artifak lain yang memengaruhi hasil-hasil penelitian yang saling berlawanan (Hunter \& Schmidt, 1990). Studi meta analisis dilakukan untuk mengkaji keajegan atau ketidakajegan hasil penelitian yang disebabkan banyaknya replikasi atau verifikasi penelitian yang berakibat pada besarnya variasi hasil penelitian (Sugiyanto, 2006). Penelitian ini bertujuan untuk mengkaji hasil penelitian yang telah dilakukan para peneliti sebelumnya di bidang industri organisasi, apakah stres kerja secara konsisten memang berkaitan dengan kinerja melalui studi meta analisis, dengan hipotesa bahwa stres kerja berhubungan secara negatif dengan kinerja karyawan.

\section{Metode Penelitian}

Pengumpulan data pada penelitian ini menggunakan studi primer melalui penelusuran terhadap artikel-artikel dari berbagai media elektronik, dengan menggunakan fasilitas program Direct Access Online Journal EBSCO dan Proquest yang diakses melalui www. lib.ugm.ac.id ataupun mencari koleksi hasil penelitian primer di perpustakaan Fakultas Psikologi UGM dengan kata kunci stres, job stress, work stres dan job performance. Berdasarkan hasil penelusuran 
yang dilakukan oleh peneliti dengan kata kunci tersebut, maka diperoleh sebanyak 261 jurnal yang terkumpul. Selanjutnya, dilakukan proses pemilihan studi yang memiliki karakteristik studi primer yaitu mengungkap kaitan antara stres kerja dan kinerja. Berdasarkan seleksi studi primer maka diperoleh sebanyak 70 studi. Tahap berikutnya dipilih yang mempunyai informasi data tentang karakteristik subjek, jumlah subjek (N), nilai korelasi (r), dan koefisien reliabilitas $\left(\mathbf{r}_{\mathrm{xy}}\right)$. Penekanan proses seleksi ini lebih kepada adanya infornasi tentang karakteristik subjek, jumlah subjek $(\mathrm{N})$, dan nilai korelasi (r) baik yang memiliki nilai positif ataupun negatif. Selanjutnya, informasi yang berkaitan dengan koefisien reliabilitas $\left(\mathbf{r}_{\mathbf{x y}}\right)$ dari studi primer tidak begitu ditekankan, artinya studi primer masih dapat diikutsertakan bila tidak diketahui koefisien reliabilitasnya $\left(\mathbf{r}_{\mathbf{x y}}\right)$. Oleh karena itu, berdasarkan kriteria tersebut akhirnya terpilih 19 studi yang digunakan untuk kajian dalam meta analisis ini.

Sebelum melakukan sintesa dari beberapa hasil penelitian, terlebih dahulu dilakukan koreksi terhadap artifak atau ketidaksempurnaan penelitian. Meta analisis digunakan sebagai dasar untuk menolak atau menerima hipotesis yang diajukan. Pada penelitian ini dilakukan 2 (dua) artifak yang dianalisis, yaitu kesalahan sampling dan kesalahan pengukuran (Hunter \& Smith, 1990):

1. Kesalahan sampling dianalisis dengan cara: a) Menghitung estimasi r populasi $(\check{r})$

b) Menghitung varians $r$ populasi terbobot $\left(\sigma^{2} r\right)$

c) Menghitung varians kesalahan pengambilan sampel $\left(\sigma^{2} e\right)$

d) Menghitung estimasi varians korelasi populasi yang sesungguhnya $\left(\sigma^{2} \rho\right)$

e) Menentukan interval kepercayaan

f) Menghitung dampak kesalahan pengambilan sampel

2. Kesalahan pengukuran dianalisis dengan cara

a) Koreksi kesalahan pengukuran variabel independen

b) Koreksi kesalahan pengukuran variabel dependen

c) Koreksi kesalahan pengukuran

d) Rerata kesalahan pengukuran pada variabel $\mathrm{x}$ dan y yang diperoleh dari rerata a

e) Estimasi r populasi yang ditunjukkan dengan simbol rp yang diperoleh dari rerata/ rerata

Berikut beberapa tahap analisis data studi yang dilakukan:

1. Koreksi kesalahan pengambilan sampel Adapun karateristik sampel dapat dilihat pada tabel 1. Sampel terdiri dari karyawan perusahan/ industri, polisi, akuntan, perawat, jurnalist, dan lain sebagainya. Adapun perhitungan untuk koreksi sampling tercantum dalam tabel 2.

Tabel 1.Karakteristik Sampel Penelitian

\begin{tabular}{|c|c|c|c|c|c|c|c|}
\hline Studi & Tahun & Peneliti & $\mathrm{N}$ & $\mathrm{r}$ & Pekerjaan & Laki-laki & Perempuan \\
\hline 1 & 2004 & $\begin{array}{l}\text { Hsieh, H-L., Huang, L-C., } \\
\text { Su, K-J. }\end{array}$ & 447 & $-0,172$ & $\begin{array}{l}\text { Karyawan Hi-tech } \\
\text { industri }\end{array}$ & - & - \\
\hline 2 & 2008 & $\begin{array}{l}\text { Kazmi, R., Amjad, S., \& } \\
\text { Khan, D. }\end{array}$ & 55 & $-0,718$ & $\begin{array}{l}\text { Karyawan Rumah } \\
\text { Sakit }\end{array}$ & 31 & 21 \\
\hline
\end{tabular}




\begin{tabular}{|c|c|c|c|c|c|c|c|}
\hline 3 & 2008 & $\begin{array}{l}\text { Abualrub, R. F., \& Al- } \\
\text { Zaru, I. M }\end{array}$ & 206 & $-0,21$ & Perawat & 92 & 114 \\
\hline 4 & 2008 & $\begin{array}{l}\text { Chen, J-C., \& Silverthorne, } \\
\text { C }\end{array}$ & 209 & $-0,316$ & Akuntan & 38 & 171 \\
\hline 5 & 2009 & Chen, Y., F. & 787 & $-0,724$ & Polisi & - & - \\
\hline 6 & 2010 & Hamidi, Y., \& Eivazi, Z. & 120 & 0,69 & $\begin{array}{l}\text { Karyawan Pusat } \\
\text { Kesehatan }\end{array}$ & - & - \\
\hline 7 & 2010 & Bashir, U., \& Ramay, M. I. & 144 & $-0,527$ & $\begin{array}{l}\text { Supervisor \& } \\
\text { Manager }\end{array}$ & 125 & 19 \\
\hline 8 & 2011 & Ali, F., \& et al. & 47 & 0,315 & Karyawan Bank & 36 & 11 \\
\hline 9 & 2011 & Wu, Y. C. & 571 & $-0,100$ & Karyawan & - & - \\
\hline 10 & 2011 & Yeh, S. P., \& Chao, P. F., & 51 & $-0,516$ & Jurnalist & - & - \\
\hline 11 & 2011 & $\begin{array}{l}\text { Mohsan, F., Musarrat } \\
\text { N.M., \& Khan, M. S. }\end{array}$ & 112 & $-0,18$ & Karyawan Bank & 90 & 22 \\
\hline 12 & 2011 & Jamal, M. & 305 & $-0,35$ & Karyawan Malaysia & 238 & 67 \\
\hline 13 & 2011 & Jamal, M. & 325 & $-0,39$ & Karyawan Pakistan & 286 & 39 \\
\hline 14 & 2011 & $\begin{array}{l}\text { Leung, M-Y., Chan, Y. S.I., } \\
\text { \& Dongyu, C. }\end{array}$ & 108 & $-0,22$ & Manajer Proyek & 94 & 14 \\
\hline 15 & 2012 & Yang, C. Y., \& Hung, C. H. & 243 & $-0,778$ & Karyawan restoran & - & - \\
\hline 16 & 2012 & $\begin{array}{l}\text { Khalid, A., Murtaza, G.., } \\
\text { Zafar, A., Zafar, M. A., } \\
\text { Saqib, L., \& Mushtaq, R }\end{array}$ & 169 & $-0,235$ & Karyawan & - & - \\
\hline 17 & 2012 & Atteya, N. M. & 780 & $-0,483$ & Supervisor Hotel & 546 & 234 \\
\hline 18 & 2013 & $\begin{array}{l}\text { Ajayi, M. P., \& Abimbola, } \\
\text { H. O. }\end{array}$ & 225 & $-0,77$ & $\begin{array}{l}\text { Karyawan } \\
\text { Perusahaan }\end{array}$ & 119 & 106 \\
\hline 19 & 2013 & $\begin{array}{l}\text { Azizollah, A., Zaman, A., } \\
\text { \& Khatam-Al, O.K. }\end{array}$ & 100 & $-0,42$ & Perawat & - & - \\
\hline
\end{tabular}

Bare-Bones meta-analysis dilakukan untuk mengetahui koreksi kesalahan pengambilan sampel (Hunter \& Schmidt, 2004). Estimasi kesalahan sampel ini dihitung melalui rerata korelasi Populasi $(\breve{r})$ dengan menggunakan rumus:

$$
\check{r}=\frac{\Sigma\left(N \cdot r_{X Y}\right)}{\Sigma \mathrm{N}}
$$

Berdasarkan rumus tersebut maka dilakukan proses perhitungan dengan menggunakan program Microsoft Excel sesuai yang tercantum pada tabel 2 di bawah ini.

Tabel 2.Rerata Korelasi Populasi

\begin{tabular}{cccc}
\hline Studi & $\mathrm{N}$ & $\mathrm{r}_{\mathrm{XY}}$ & $\mathrm{N} \mathrm{x} \mathrm{r}_{\mathrm{XY}}$ \\
\hline 1 & 447 & $-0,172$ & $-76,884$ \\
2 & 55 & $-0,718$ & $-39,490$ \\
3 & 206 & $-0,21$ & $-43,260$ \\
4 & 209 & $-0,316$ & $-66,044$ \\
5 & 787 & $-0,724$ & $-569,788$ \\
6 & 120 & 0,69 & 82,800 \\
7 & 144 & $-0,527$ & $-75,888$ \\
8 & 47 & 0,315 & 14,805
\end{tabular}




\begin{tabular}{cccc}
9 & 571 & $-0,100$ & $-57,100$ \\
10 & 51 & $-0,516$ & $-26,316$ \\
11 & 112 & $-0,18$ & $-20,160$ \\
12 & 305 & $-0,35$ & $-106,750$ \\
13 & 325 & $-0,39$ & $-126,750$ \\
14 & 108 & $-0,22$ & $-23,760$ \\
15 & 243 & $-0,778$ & $-189,054$ \\
16 & 169 & $-0,235$ & $-39,715$ \\
17 & 780 & $-0,483$ & $-376,740$ \\
18 & 225 & $-0,77$ & $-173,250$ \\
19 & 100 & $-0,42$ & $-42,000$ \\
Total & 5004 & $-2,288$ & $-1955,344$ \\
Mean & 263,36842 & $-0,1204211$ & $-0,391$ \\
\hline
\end{tabular}

Perhitungan varians $r_{x y}$ tercantum data primer di atas,terdapat 9 studi yang dalam tabel 2 di atas, dan korelasi populasi mempunyai nilai korelasi di bawah rerata yang sesungguhnya setelah dikoreksi dengan korelasi populasi dan 10 studi di atas nilai kesalahan pengambilan sampel adalah rerata korelasi populasi. sebesar -0.391. Berdasarkan pengolahan

Tabel 3.Varians Korelasi Populasi Terbobot

\begin{tabular}{cccccc}
\hline No & $\mathrm{N}$ & $\mathrm{r}_{\mathrm{XY}}$ & $\mathrm{r}_{\mathrm{XY}}-\mathrm{r}$ & $\left(\mathrm{r}_{\mathrm{XY}}-\mathrm{r}\right)^{2}$ & $\mathrm{~N} \mathrm{x}\left(\mathrm{r}_{\mathrm{XY}}-\mathrm{r}\right)^{2}$ \\
\hline 1 & 447 & $-0,172$ & 0,219 & 0,048 & 21,391 \\
2 & 55 & $-0,718$ & $-0,327$ & 0,107 & 5,890 \\
3 & 206 & $-0,21$ & 0,181 & 0,033 & 6,731 \\
4 & 209 & $-0,316$ & 0,075 & 0,006 & 1,168 \\
5 & 787 & $-0,724$ & $-0,333$ & 0,111 & 87,397 \\
6 & 120 & 0,69 & 1,081 & 1,168 & 140,164 \\
7 & 144 & $-0,527$ & $-0,136$ & 0,019 & 2,673 \\
8 & 47 & 0,315 & 0,706 & 0,498 & 23,410 \\
9 & 571 & $-0,100$ & 0,291 & 0,085 & 48,272 \\
10 & 51 & $-0,516$ & $-0,125$ & 0,016 & 0,800 \\
11 & 112 & $-0,18$ & 0,211 & 0,044 & 4,975 \\
12 & 305 & $-0,35$ & 0,041 & 0,002 & 0,507 \\
13 & 325 & $-0,39$ & 0,001 & 0,000 & 0,000 \\
14 & 108 & $-0,22$ & 0,171 & 0,029 & 3,149 \\
15 & 243 & $-0,778$ & $-0,387$ & 0,150 & 36,440 \\
16 & 169 & $-0,235$ & 0,156 & 0,024 & 4,100 \\
17 & 780 & $-0,483$ & $-0,092$ & 0,009 & 6,637 \\
18 & 225 & $-0,77$ & $-0,379$ & 0,144 & 32,361 \\
19 & 100 & $-0,42$ & $-0,029$ & 0,001 & 0,086 \\
Total & 5004 & $-2,288$ & 1,320 & 2,492 & 426,150 \\
Mean & 263,36842 & 0,1204211 & 0,000 & 0,000 & 0,085 \\
\hline & & & & &
\end{tabular}


Berdasarkan tabel 3 di atas, diketahui varians $r_{x y}$ sebesar 0,085 . Varians kesalahan pengambilan sampel $\left(\sigma^{2} e\right)$ sebesar 0,002736 , standar deviasi (SD) sebesar 0,287098. Dengan menggunakan interval kepercayaan 95\%, maka nilai korelasi sebesar $-0,391$ masih dalam batas interval kepercayaan. Berdasarkan hal ini dapat disimpulkan bahwa ada hubungan negatif antara stres kerja dengan dengan kinerja, sehingga hipotesa diterima.
2. Koreksi kesalahan pengukuran

Variabel dalam kinerja tidak pernah dapat diukur secara sempurna karena setiap pengukuran akan mengandung error yang akan melemahkan koefisien korelasi. Kesalahan pengukuran mempunyai status yang khusus di antara artifak yang sistematis, karena artifak ini selalu ada dalam di setiap pengukuran.

Tabel 4.Estimasi Kesalahan Pengukuran

\begin{tabular}{cccccccc}
\hline No & $\mathrm{N}$ & $\mathrm{r}_{\mathrm{XY}}$ & $\mathrm{Nx}\left(\mathrm{r}_{\mathrm{XY}}-\mathrm{r}\right)^{2}$ & $\mathrm{raa}$ & $(\mathrm{a})$ & $\mathrm{Rbb}$ & $(\mathrm{b})$ \\
\hline 1 & 447 & $-0,172$ & 21,391 & - & - & - & - \\
2 & 55 & $-0,718$ & 5,890 & - & - & - & - \\
3 & 206 & $-0,21$ & 6,731 & 0,85 & 0,9220 & 0,96 & 0,9798 \\
4 & 209 & $-0,316$ & 1,168 & 0,77 & 0,8775 & 0,75 & 0,8660 \\
5 & 787 & $-0,724$ & 87,397 & 0,912 & 0,9550 & 0,869 & 0,9322 \\
6 & 120 & 0,69 & 140,164 & - & - & - & - \\
7 & 144 & $-0,527$ & 2,673 & 0,694 & 0,8331 & 0,637 & 0,7981 \\
8 & 47 & 0,315 & 23,410 & - & - & - & - \\
9 & 571 & $-0,100$ & 48,272 & - & - & - & - \\
10 & 51 & $-0,516$ & 0,800 & 0,843 & 0,9182 & 0,929 & 0,9638 \\
11 & 112 & $-0,18$ & 4,975 & - & - & - & - \\
12 & 305 & $-0,35$ & 0,507 & 0,86 & 0,9274 & 0,85 & 0,9220 \\
13 & 325 & $-0,39$ & 0,000 & 0,89 & 0,9434 & 0,88 & 0,9381 \\
14 & 108 & $-0,22$ & 3,149 & 0,785 & 0,8860 & 0,813 & 0,9017 \\
15 & 243 & $-0,778$ & 36,440 & 0,812 & 0,9011 & 0,836 & 0,9143 \\
16 & 169 & $-0,235$ & 4,100 & 0,923 & 0,9607 & 0,93 & 0,9644 \\
17 & 780 & $-0,483$ & 6,637 & 0,74 & 0,8602 & 0,82 & 0,9055 \\
18 & 225 & $-0,77$ & 32,361 & - & - & - & - \\
19 & 100 & $-0,42$ & 0,086 & 0,84 & 0,9165 & 0,89 & 0,9434 \\
Total & 5004 & $-2,288$ & 426,150 & 9,919 & 10,9010 & 10,164 & 11,0293 \\
\hline & & & & & & - \\
\hline
\end{tabular}

Koefisien korelasi populasi setelah dilakukan koreksi kesalahan pengukuran, baik yang terdapat pada variabel independen ataupun dependen adalah sebesar $-0,549$. Korelasi populasi sesungguhnya $(\rho)$ diestimasikan sebesar Varians kesalahan pengukuran adalah sebesar 0,1611963, dan standar deviasi (SD) sebesar 0,40149259.
Dengan menggunakan Interval kepercayaan sebesar 95\% maka korelasi tersebut dapat dikatakan dalam batas yang diterima. Kesimpulan dari perhitungan ini adalah ada hubungan yang negatif antara stres kerja dengan kinerja, dengan dampak variasi reliabilitas sebesar $1,02 \%$. Variasi sebesar ini menunjukkan korelasi yang berbeda 
antara mean populasi dengan mean studi dalam penelitian yang disebabkan adanya kesalahan pengukuran sebesar $1,02 \%$.

Berdasarkan kesalahan dalam pengambilan sampel dan kesalahan dalam pengukuran, maka hipotesis penelitian diterima, yaitu ada korelasi negatif antara stres kerja dengan kinerja.

\section{Hasil dan Pembahasan}

Hasil studi meta analisis yang telah dilakukan peneliti menunjukkan adanya korelasi negatif antara stres kerja dengan kinerja, baik dari hasil olah data berdasarkan kesalahan dalam pengambilan sampel ataupun kesalahan dalam pengukuran. Berdasarkan kesalahan dalam pengambilan sampel, terlihat ada korelasi sebesar -0,391 antara stres kerja dengan kinerja karyawan, dimana varians kesalahan adalah sebesar 0,002736 dan penyimpangan atau standar deviasi sebesar 0,287098, dengan tingkat kepercayaan 95\% $(\mathrm{p}<0.05)$ (hipotesa diterima). Berdasarkan kesalahan dalam pengukuran, terlihat ada korelasi sebesar -0,549 antara stres kerja dengan kinerja karyawan, dimana varians kesalahan sebesar 0,1611963 dan penyimpangan atau standar deviasi sebesar 0,40149259, dengan tingkat kepercayaan sebesar 95\% $(\mathrm{p}<0.05)$ (hipotesa diterima).

Berdasarkan kesalahan pengambilan sampel dan kesalahan pengukuran menunjukkan adanya korelasi negatif antara stres kerja dengan kinerja karyawan. Hal ini sesuai dan menguatkan hasil studi penelitian yang dilakukan oleh para peneliti sebelumnya yang secara umum menunjukkan bahwa stres kerja memiliki pengaruh kinerja karyawan. Korelasi antara stres kerja dengan kinerja berdasarkan hasil penelitian menunjukkan arah yang negatif, artinya semakin tinggi stres kerja yang dialami karyawan, maka akan semakin rendah pula kinerjanya. Temuan penelitian ini mendukung penelitian Pincherle (1972) bahwa stres kerja bersifat menganggu kinerja, semakin tinggi stres kerja maka semakin tinggi pula tingkat gangguan pada kinerja. Schult \& Schult (1994) juga menyatakan bahwa stres kerja adalah gejala psikologis yang dirasakan mengganggu dalam pelaksanaan tugas sehingga dapat mengancam eksistensi diri dan kesejahteraan anggota organisasi, dan jika situasi yang mengancam tersebut terjadi dalam jangka waktu yang relatif lama maka dapat mengganggu proses identifikasi diri anggota terhadap organisasi dan nilainilai serta tujuan organisasi. Begitupula dengan hasil penelitian yang dilakukan oleh Hidayati, Purwanto, \& Yuwono (2010) yang menunjukan bahwa stres yang dialami oleh karyawan akan berakibat negatif terhadap kinerjanya apabila yang terjadi adalah distress.

Secara umum, Evan \& Johnson (2000); Vakola \& Nikolaou (2005) menyebutkan bahwa stres kerja merupakan faktor yang menentukan naik turunnya kinerja karyawan terhadap organisasi. Secara teoritis dan praktis bahwa stres kerja memang tidak selalu secara otomatis berdampak buruk terhadap kinerja karyawan. Secara umum stres kerja yang dialami karyawan berpeluang menurunkan kinerja karyawan, namun di waktu/ kondisi yang berbeda atau dengan kata lain pada kasus tertentu stres kerja justru dapat meningkatkan performa/kinerja karyawan dalam bekerja. Sesuai dengan yang disampaikan oleh Lori, Stanley, dan Hubert (2003) tentang studi ulasan yang dilakukannya selama 25 tahun, sejak tahun 1978 tentang stres-kinerja. Hasil kajian mereka menunjukkan bahwa hubungan antara stres kerja dan kinerja tetap mengalami kontroversi, dimana terkait dengan apakah hubungan antara stres kerja 
dan kinerja terbaik memiliki hubungan positif, hubungan negatif, atau sebagai inverted- $U$. Beberapa argumen teoritis yang disediakan dalam literatur mendukung efek yang merugikan dari stres kerja pada kinerja, namun di sisi lain berbicara tentang efek positif dari stres kerja yang dialami terhadap kinerja.

Jex (1998) berpendapat bahwa stres kerja tidak hanya memiliki hubungan negatif terhadap kinerja, hal tersebut dikarenakan adanya perbedaan kemampuan, gaya berpikir, kepribadian dan sistem nilai yang dianut oleh individu. Minter (1999) menjelaskan bahwa stres kerja tidak otomatis berdampak buruk terhadap kinerja karyawan, hanya saja apabila stres kerja sudah melewati ambang batas normal, maka akan memengaruhi kinerja. Hal tersebut sesuai dengan yang disampaikan oleh Selye (1976), bahwa tidak semua stres merupakan kondisi yang negatif. Selye $(1974,1977)$ juga mengatakan bahwa stres "tidak apa-apa" jika dialami oleh seseorang, namun terkait dengan bagaimana seseorang bersikap dalam menghadapinya. Stres yang bersifat destruktif adalah distres, dan eustres merupakan kekuatan yang bersifat positif. Mengalami stres dianggap sebagai suatu kewajaran/ sesuatu yang bersifat normal, hanya saja stres dapat berdampak positif ataupun negatif tergantung bagaimana seseorang menyikapinya. Hasil penelitian yang dilakukan oleh Hsieh, et al., (2004); Wetzel, Kneebone, Woloshynowych, Moorthy, Darsy, (2006) menjelaskan bahwa kemampuan karyawan untuk mengelola stres baik dari sisi fisiologis ataupun psikologis memiliki dampak yang signifikan terhadap kinerja.

Oleh karena itu, hal yang penting diketahui adalah pada saat kapan saja stres kerja akan menghasilkan eustres dan distres merupakan pertanyaan yang penting untuk dijawab. Stres kerja yang sudah melewati ambang batas normal akan menimbulkan distress. Stres kerja akan semakin tinggi apabila para anggota mendapatkan beban kerja, atau tambahan tugas yang berbeda-beda tanpa mendapatkan pelatihan sebelumnya dan jaminan perawatan kesehatan, sehingga kinerja akan menjadi turun (Minter, 1999). Shahu dan Gole (2008) juga menjelaskan bahwa stres merupakan kondisi mental dan fisik yang memiliki pengaruh terhadap kinerja, efektivitas, kesehatan, serta kualitas kerja karyawan. Stres yang berkaitan dengan pekerjaan dapat menyebabkan munculnya beberapa kondisi seperti ketegangan, kecemasan, kejengkelan, kejenuhan, dan sikap yang menunda-nunda pekerjaan (Steffy \& Jones, 1988) yang pada akhirnya dapat memengaruhi komitmen dan kinerja karyawan pada suatu organisasi. Soeharso \& Christie (2009) menyatakan bahwa stres yang terjadi secara berlarut-larut dalam kurun waktu yang cukup lama berpotensi membuat karyawan berpikir untuk mencari tempat yang lebih menyenangkan dalam bekerja, sehingga sikap tersebut akan diikuti dengan perilaku mengundurkan diri. Looker (2005) menjelaskan bahwa stres yang terlalu besar akan mengakibatkan kinerja menurun karena stres mengganggu pelaksanaan pekerjaan, dimana karyawan akan kehilangan kemampuan untuk mengendalikannya. Akibat yang paling ekstrem adalah kinerja menjadi nol, karyawan menjadi tidak kuat lagi bekerja, putus asa, keluar atau menolak bekerja untuk menghindari stres.

Di sisi lain, stres dibutuhkan untuk menghasilkan prestasi yang tinggi, karena tingkat stres yang optimal akan membuat karyawan bersemangat dan termotivasi dalam berkerja. Dapat dikatakan bahwa jika tidak ada stres, maka tantangan kerja juga tidak ada dan kinerja dimungkinkan cenderung mengalami penurunan. Hal tersebut sesuai 
dengan hasil studi yang dilakukan Meglino (1977) yang menunjukkan bahwa jika tingkat stres rendah, tantangan tidak ada, maka akibatnya kinerja menjadi buruk. Rangsangan yang terlalu kecil, tuntutan dan tantangan yang terlampau sedikit dapat menyebakan kebosanan, frustasi, dan perasaan bahwa kita tidak sedang menggunakan kemampuan-kemampuan kita secara penuh (Looker, 2005). Sejalan dengan meningkatnya stres maka kinerja akan cenderung naik, karena stres mampu membantu karyawan mengarahkan segala sumber kemampuan yang dimiliki untuk memenuhi kebutuhan kerja. Pendapat tersebut diperkuat oleh Hatton, Brown, Caine, dan Emerson. (1995); Kahn dan Long (1988) bahwa stres merupakan tantangan yang meningkatkan kinerja. Selain itu, stres kerja yang dialami merupakan suatu rangsangan sehat yang mendorong para karyawan untuk menanggapi tantangan pekerjaan yang pada akhirnya stres dapat mencapai titik stabil yang sesuai sesuai dengan kemampuan prestasi karyawan. Ismail, Yao, dan Yunus (2009) menjelaskan bahwa individu yang mengalami eustres akan mampu memenuhi tuntutan pekerjaan, dan hal tersebut dapat membantu mereka untuk meningkatkan kehidupan kerja yang positif (misalnya, kepuasan dan nilai-nilai moral positif).

Bakker dan Demerouti (2007); Colligan dan Higgins (2005) menjelaskan penyebab langsung dari stres di tempat kerja yang meliputi adanya kelebihan beban kerja dan sumber daya tidak memadai yang dimiliki organisasi. Selain itu, persepsi karyawan memiliki peran penting sebagai penejelasan dari distres ataupun eustres yang dialami oleh karyawan (Lefevre, Matheny, \& Kolt, 2003). Hal tersebut sesuai dengan pendapat Hart dan Wearing (1995) yang membuat poin bahwa stres tidak dapat dinyatakan sebagai variabel tunggal dan bahwa terdapat unsur-unsur seperti karakteristik kepribadian, proses coping dan pengalaman kerja positif ataupun negatif yang harus dipertimbangkan karena akan memunculkan efek yang berbeda dari setiap stres yang dialami oleh karyawan. Bakker dan Demerouti (2007) mencatat karakteristik pekerjaan, partisipasi dalam mengambil keputusan merupakan variabel penting untuk mengendalikan ketegangan dalam pekerjaan. Karakteristik dari pekerjaan menekankan pada potensi motivasi sumber daya yang terkait dengan level tugas, kemandirian, umpan balik, dan signifikansi dari tugas. Clarke dan Cooper (2000) yang memfokuskan penelitian mereka pada hal-hal yang mempengaruhi stres pekerja menjelaskan bahwa stres kerja dirasakan bersifat negatif, dan stres kerja dimoderasi oleh adanya perbedaan karakteristik dari individu.

\section{Simpulan}

Berdasarkan hasil studi dapat disimpulkan bahwa stres kerja merupakan faktor penting yang dapat memengaruhi kinerja karyawan. Stress yang dialami karyawan secara umum dapat meliputi dua bentuk, yaitu eustres dan distres. Eustres ataupun distres yang dialami karyawan diindikasikan karena beberapa hal diantaranya; kelebihan beban kerja dan sumber daya yang tidak memadai, persepsi karyawan terhadap stres yang dialami, karakteristik kepribadian, proses coping, pengalaman kerja positif ataupun negatif, karakteristik pekerjaan, serta partisipasi karyawan dalam mengambil keputusan di organisasi. Hasil meta analisis pada studi ini menunjukkan bahwa stres kerja memberikan kontribusi pada kinerja dengan arah negatif. Hasil studi menunjukkan bahwa stres kerja 
yang dialami keryawan lebih mengarah pada terjadinya distres, dimana stres kerja yang dialami karyawan sudah melewati ambang batas normal, sehingga stres yang dialami memengaruhi kondisi mental dan fisik karyawan yang berimplikasi pada penurunan kinerja karena stres telah mengganggu proses pelaksanaan pekerjaan mereka.

\section{Daftar Pustaka}

Abualrub, R. F., \& Al-Zaru, I. M. (2008). Job stress, recognition, job performance and intention to stay at work among Jordanian hospital nurses. Journal of Nursing Management, 16, 227-236.

Ajayi, M. P., \& Abimbola, H. O. (2013). Job satisfaction, organizational stress and employee performance. Ife Psychologia, 21(2), 75-82.

Al Ahmadi, H. (2009). Factors affecting performance of hospital nurses in Riyadh Region, Saudi Arabia. International Journal of Health Care Quality Assurance, 22 (1), 40-54.

Ali, F., \& et al.,. (2011). Effects of Stress on job performance. International Journal of Business and Management Tomorrow "IJBMT", 1 (2), 1-7.

Atteya, N. M. (2012). Role stress measure, methods of coping with stress, and job performance: An Exploratory Study. Journal of Organizational Psychology, 12 (2). 30-51.

Azizollah, A., Zaman, A., \& Khatam-Al, O. K. (2013). The relationship between job stress and performance among the hospitals nurses. World of Sciences Journal, 02, 181-188.

Babin, B.J. \& J.S. Boles. (1998). Employee behavior in a service environment: a model and test of potential differences between men and women. Journal of Marketing, 62, 77-91.

Bakker, A. B., Demerouti, E. \& Verbeke, W. (2004). Using the job demandsresources model to predict burnout and performance. Human Resource Management, 43 (1), 83-104.

Bakker, A.B. and Demerouti, E. (2007). The job demands-resources model: state of the art. Journal of Managerial Psychology. 22(3), 309-328.

Bashir, U., \& Ramay, M. I. (2010). Impact of stress on employees job performance a study on banking sector of Pakistan. International Journal of Marketing Studies, 2, (1), 122-126.

Beehr, T. A., \& Newman, J. E. (1988). Psychological stress in the workplace. London: Routledge.

Bono, J.E. \& T.A. Judge. (2003). Selfconcordance at work: toward understanding the motivational effects of transformational leaders. Academy of Management Journal, 46, (5), 554571

Boyatzis, R,E. (1999). Unleashing the power of self directed learning. Cleveland, Ohio, USA : Case Western Reserve University.

Brown, S.P. (1996). A Meta-analysis and review of organizational research on job involvement. Psychological Bulletin, 120, 235-255.

Cascio, W. F. (1991). Applied psychology in personnel management (4th ed.). Englewood Cliffs, NJ: Prentice-Hall.

Chen, J-C., \& Silverthorne, C. (2008). 
The impact of locus of control on job stress, job performance and job satisfaction in Taiwan. Leadership \& Organization Development Journal, 29 (7), 572-582.

Chen, Y-F. (2009). Job stress and performance: a study of police officers in Central Taiwan. Social Behavior and Personality, 37(10), 1341-1356.

Chermiss, C. (1998). Working with emotional intelligence, the consortium for research on emotional intelligence in organizations. New Jersey: Rugrets University.

Clarke, S.G., Cooper, C.L. (2000). The risk management of occupationalstress. Health Risk Soc., 2(2), 173-187

Cleveland, J. N., Murphy, K. R., \& Williams, R. E. (1989). Multiple uses of performance appraisal: prevalence and correlates. Journal of Applied Psychology, 74, 130-135.

Colligan, T.W. and Higgins, E.M. (2005). Workplace stress: etiology and consequences. Journal of Workplace Behavioural Health. 21(2): 89-97.

D'Amato, A. and Zijlstra, F.R.H. (2008). Psychological climate and individual factors as antecedents of work outcomes. European Journal of Work and Organisational Psychology, 17 (1), 33-54.

Diefendorff, J., Brown, D., Kamin, A., and Lord, B. (2002). Examining the roles of job involvement and work centrality in predicting organizational citizenship behaviours and job performance. Journal of Organizational Behaviour, 23, 93-108.

Dokko, G.,. Wilk, S. L.,. \& Rothbard, N. P.
(2008). Unpacking prior experience: how career history affects job performance. organization science, Articles in Advance, 1-18,

Evan, G. W., \& Johnson, D. (2000). Stress and open office noise. Journal of Applied Psychology, 85, 779-783.

Fahmi, I. (2010). Manajemen kinerja (teori dan aplikasi). Bandung : Alfabeta.

Ferris, D. L. , Lian, H., Brown, D. J., Pang, F. X. J., \& Keeping, L. M. (2010). Self-esteem and job performance: the moderating role of self-esteem contingencies. Personnel Psychology, 63, 561-593

Goleman, D. (2001). Kecerdasan emosi untuk mencapai puncak prestasi : Jakarta : Gramedia.

Gu, Z., \& Chi, R.S.S. (2009). Drivers of job satisfaction as related to work performance in Macao Casino Hotels: an investigation based on employee survey. International Journal of Contemporary Hospitality Management, 21 (5), 561-578.

Hamidi, Y., \& Eivazi, Z. (2010). The relationships among employees, job stress, job satisfaction, and the organizational performance of Hamadan Urban Health Centers. Social Behavior and Personality, 38(7), 963-968.

Hatton, C., Brown, R., Caine, A., \& Emerson, E. (1995). Coping strategies and stress-related outcomes among direct care staff in staffed house for people with learning disabilities. Mental Handicap Res., 8, 252-271.

Hidayati, R., Purwanto, Y., \& Yuwono, S. (2010). Korelasi kecerdasan emosi 
dan stres kerja dengan kinerja. Jurnal Ilmiah Psikologi "Indigenous", 12, 81-87.

Hsieh, H-L., Huang, L-C., Su, K-J. (2004). Work stress and job performance in the Hi-Tech industry: A Closer View for Vocational Education. World Transactions on Engineering and Technology Education, 3(1), 147-150.

Hart, P.M., \& Wearing, A.J. (1995). Occupational stress and well-being: A systematic approach to research, policy and practice. In: P Cotton (Ed.), Psychological health in the workplace. Australian Psychology Society, Victoria, Australia, 185-216.

Hunter, J. E. \& Schmidt, F. S. (1990). Methods of meta-Analysis. New Delhi: Sage Publication.

Hunter, J.E., \& Schmidt, F.L. 2004. Methods of meta-analysis: Correcting error and bias in research findings. 2nd ed. Thousand Oaks: Sage Publications, Inc.

Ismail, A., Yao, A., Yunus, N. K. Y. (2009). Relationship between occupational stress and job satisfaction: an empirical study in Malaysia. The Romanian Economic Journal, no. 34 (4), 3-27.

Ivancevich, J,M. (2001). Human resource management, 8th Edition. New York : McGraw Hill.

Jamal, M. (2011). Job stress, job performance and organizational commitment in a multinational company: an empirical study in two countries. International Journal of Business and Social Science, 2 (20), 20-29

Jaramilloa, F., Mulki, J.P., \& Marshall, G.W. (2005). A Meta-analysis of the relationship between organisational commitment and salesperson job performance: 25 years of research. Journal of Business Research, 58, 705- 714 .

Jex, S.M., (1998). Stress andjob performance. London: Sage Publications

Johns, G. (1996). Organizational Behavior. 4th editions. New York: Harper Collins.

Judge, T. A, Bono, J. E, Thoresen, C. J, \& Patton, G. K. (2001). The job satisfaction-job performance relationship : a qualitative and quantitative review. Psychological Bulletin, 127 (3), 376-407.

Kahn, S. E., \& Long, B.C. (1988). Workrelated stress, self-efficacy, and wellbeing of female clerical workers. Counsel. Psychol. Q., 1, 145-153.

Karatepea, O.M., Uludagb, O., Menevisc, I., Hadzimehmedagicc, L., \& Baddarc, L. (2006). The effects of selected individual characteristics on frontline employee performance and job satisfaction. Tourism Management, 27, 547-560.

Kazmi, R., Amjad, S., \& Khan, D. (2008). Occupational stress and its effect on job performance a case study of medical house officers of District Abbottabad. J Ayub Med Coll Abbottabad, 20 (3), 135-139.

Khalid, A., Murtaza, G.., Zafar, A., Zafar, M. A., Saqib, L., \& Mushtaq, R. (2012). Role of supportive leadership as a moderator between job stress and job performance. Information Management and Business Review, 4 (9), 487-495. 
Knight, D. K., Kim, H. J., \& Crutsinger, C. (2007). Examining the effects of role stress on customer orientation and job performance of retail sales people. International Journal of Retail and Distribution Management, 35 (5), 381-392.

Leung, M-Y., Chan, Y. S.I., \& Dongyu, C. (2011). Structural linear relationships between job stress, burnout, physiological stress, and performance of construction project managers. Engineering, Construction and Architectural Management, 18 (3), 312-328.

Lefevre, M.L., Matheny, J. and Kolt, G.S. (2003). Eustress, distress and interpretation in occupational stress. Journal of Managerial Psychology. 18(7), 726-744.

Levey, R.E. (2001). Sources of stress for residents and recommendations for programs to assist them. Acad Med, $76,142-50$.

Lori, A.M., Stanley, G.H., \& Hubert, S.F. (2003). Has the inverted-u theory of stress and job performance had a fair test? Hum. Perform., 16(4), 349-364.

Luthans, F. (1998). Organizational behavior. Singapore: McGraw-Hill Books Company.

Mathis, R,L, \& Jackson. (2002). Manajemen sumber daya manusia, Jilid 1 dan 2. (Alih bahasa : Bayu Brawira). Jakarta : Salemba Empat.

Meglino, B.M. (1977). Stress and performance: Are they always incompatible?. Supervisory Manage, 22, 2-12.
Minter, S.G. (1999). Too much stress? Occupational Hazard, 06, 49-52.

Mohsan, F., Musarrat Nawaz, M., \& Khan, M. S. (2011). Impact of stress on job performance of employees working in banking sector of Pakistan. Interdisciplinary Journal of Contemporary Research In Business, 3 (2), 1982-1991.

Motowidlo, S. J., Borman, W. C., \& Schmit, M. J. (1997). A Theory of Individual differences in task and contextual performance. Human Performance, 10, 71-83.

Mount, M. K., \& Barrick, M. R. (1998). Five reasons why the "big five" article has been frequently cited. Personnel Psychology, 51, 849-857.

Muchinsky, P. M. (2003). Psychology applied to work (7th ed.). Belmont, CA: Wadsworth.

Ng, T. W. H. \& Feldman, D.C. (2009). How broadly does education contribute to job performance? Personnel Psychology; 62 (1), 89.

Pincherle, G. 1972. Assesment of Relationsip between stress and work performance. J. Royal Soc. Med., 65 (4), 321-324.

Puspita, M. D. (2012). Hubungan antara dukungan sosial dan makna kerja sebagai panggilan (calling) dengan keterikatan kerja. Calyptra: Jurnal Ilmiah Mahasiswa Universitas Surabaya, Volume 1 (1).

Riketta, M. (2008). The causal relation between job attitudes and performance: a meta-analysis of panel studies. Journal of Applied Psychology, 93 (2), 472-481 
Robbins, S. P. (2001). Teori organisasi: struktur, desain, dan aplikasi (3rd ed., Alih Bahasa: J. Udaya). Jakarta: Arcan.

Robbins, S. P. (2004). Teori organisasi, struktur, desain, dan aplikasi. (Alih Bahasa: Tim Indeks). New Jersey: Prentice Hall.

Rotenberry, P.F., \& Moberg, P.J. (2007). Assessing the Impact of job involvement on performance. Management Research News, 30, 203-215.

Saetang, J. Sulumnad, K., Thampitak, P, \& Sungkaew, T. (2010). Factors affecting perceived job performance among staff: a case study of ban karuna juvenile vocational training centre for boys. The Journal of Behavioral Science, 5 (1), 33-45.

Schultz, D. P., \& Schultz, S. E. (1994). Psychology and work today. New York: McMillan Publishing Company, Inc.

Schmidt, F. L., \& Hunter, J. E. (1992). Causal modeling of processes determining job performance. Current directions in psychological science, 1, 89-92.

Sheridan, C. L., \& Radmacher, S. A. (1992). Health Psychology: Challenging the Biomedical Model. Singapore: John Wiley and Sons, Inc.

Selye H. 1974. Stress without distress. Philadelphia, PA: J.B. Lippincott Co.

Selye H. 1976. Stress in health and disease butterworth's, Inc. Boston, MA:.

Selye H. 1977. The stress of my life: a scientist's memoirs. Toronto: McClelland and Stewart
Shahu, R. \& Gole, S.V. 2008, Effect of job stress and job satisfaction on performance: an empirical study, AIMS International Journal of Management 2 (3). 237-246.

Sheridan, C. L., \& Radmacher, S. A. (1992). Health psychology: challenging the biomedical model. Singapore: John Wiley and Sons, Inc.

Singh, J., W. Verbeke \& G.K. Rhoads. (1996). Do organizational practices matter in role stress processes? a study of direct and moderating effects for marketing-oriented boundary spanners. Journal of Marketing, 60, 69-86.

Steffy, B. \& Jones, J. (1988). Workplace stress and indicators of coronarydisease risk. Academy of Management Journal. 31(3), 686-698.

Sugiyanto. (2006). Meta analisis. Bahan perkuliahan metode kuantitatif. Tidak diterbitkan. Yogyakarta: Fakultas Psikologi UGM

Vakola, M., \& Nikolaou, I. (2005). Attitudes towards organizational change: what is the role of employees' stress and commitment?. Employee Relations, 27, 160-174.

Viswesvaran, C., Schmidt, F. L., \& Ones, D. S. (1996). Comparative analysis of the reliability of job performance ratings. Journal of Applied Psychology, 81(5), 557-574.

Viswesvaran, C., Ones, D. S., \& Schmidt, F. L. (2002). The moderating influence of job performance dimensions on convergence of supervisory and peer ratings of job performance: uconfounding construct-level 
convergence and rating difficulty. Journal of Applied Psychology, 87(2), 345-354.

Viswesvaran, C., \& Ones, D. S. (2005). Job performance: Assessment issues in personnel selection. In A. Evers, N. Anderson, \& O. Voskuijl (Eds.), The Blackwell Handbook of Personnel Selection. United Kingdom: Blackwell.

Wetze1, C.M., Kneebone, R.L., Woloshynowych, M., Moorthy, K., Darsy, A.D. (2006). The effects of stress on surgical performance, The American Journal of Surgery, 191(1), 5-10.

Wu, Y. C. (2011). Job stress and job performance among employees in the taiwanese finance sector: the role of emotional intelligence. Social Behavior And Personality, 39 (1), 21-32.
Yang, C. Y., \& Hung, C. H. (2012). Effect of recreational involvement on stress relief and job performance in restaurant workers: the moderating role of psychological contract. Pak. J. Statist. 28 (5), 525-535.

Yeh, S. P., \& Chao, P. F. (2011). The moderating effects of job stress on leisure participation and job performance among journalists. Pak. J. Statist, 27 (5), 721-731.

Yelboğa, A. (2012). Dependability of job performance ratings according to generalizability theory. Education and Science, 37 (163), 157-164. 